5 Smyth LJC, Starkey C, Vestbo J, et al. CD4-regulatory cells in COPD patients. Chest 2007; 132: 156-163.

6 Plumb J, Smyth LJC, Adams HR, et al. Increased T-regulatory cells within lymphocyte follicles in moderate COPD. Eur Respir J 2009; 34: 89-94.

7 Barcelo B, Pons J, Ferrer JM, et al. Phenotypic characterisation of T-lymphocytes in COPD: abnormal CD4+CD25+ regulatory T-lymphocyte response to tobacco smoking. Eur Respir J 2008; 31: $585-562$.

8 Lee SH, Goswami S, Grudo A, et al. Antielastin autoimmunity in tobacco smoking-induced emphysema. Nat Med 2007; 13: 567-569.
9 BTS guidelines for the management of chronic obstructive pulmonary disease. The COPD Guidelines Group of the Standards of Care Committee of the BTS. Thorax 1997; 52: Suppl. 5, S1-S28.

10 Pauwels RA, Buist AS, Calverey MA, et al. Global strategy for the diagnosis, management, and prevention of chronic obstructive pulmonary disease. Am J Respir Crit Care Med 2001; 163: 1256-1276.

11 Saetta M, Turato G, Maestrelli $P$, et al. Cellular and structural bases of chronic obstructive pulmonary disease. Am J Respir Crit Care Med 2002; 163: 1304-1309.

\title{
On the issue of exercise normalcy
}

\section{To the Editors:}

Cardiopulmonary exercise testing (CPET) has evolved as a useful tool for evaluation of exercise capacity in apparently healthy subjects. In the clinical arena, CPET is widely used to judge exercise "normalcy" in individuals with a suspected disorder and patients with several potential causes of exercise limitation [1]. In order to establish "abnormality", however, it is crucial to obtain representative frames of reference to interpret the (lack of) appropriateness of the systemic responses to exertion. Unfortunately, this is not a trivial task in the nonathletic subject as there are multiple confounding factors, especially behavioural characteristics such as the level of regular physical activity. Not surprisingly, there are only a few sets of reference values for clinical CPET interpretation which have survived the proof of time and are currently used worldwide [1].

In this context, the study recently published in the European Respiratory Journal by $\mathrm{KoCH}$ et al. [2] is welcomed. After evaluating a large sample of apparently healthy males and females with a wide range of age and body dimensions, $\mathrm{KOCH}$ et al. [2] provided a comprehensive set of prediction equations for the main CPET variables. The authors carefully avoided some well-known confounding factors, especially those related to past or current medical conditions, and the statistical analysis was unusually sophisticated.

There is, however, one major shortcoming in the study by $\mathrm{KoCH}$ et al. [2] which might hamper its application in clinical practice. Unfortunately, the participants were not randomly selected from the general population, i.e. they freely volunteered to the study as part of a larger investigation on healthrelated outcomes in Germany. Consequently, it is conceivable that the more active subjects participated, an effect that is likely to be more relevant for the older groups. In fact, the authors stated that "the influence of physical activity was not consistently significant throughout the investigated groups" [2], which suggests that the elderly group were as active as the younger subjects. The hypothesis that the study has been biased to evaluate subjects who were more active than the sedentary, general population is consistent with the higher prevalence of nonsmoking and nonhypertensive subjects in the group of volunteers compared with the complete population $(\mathrm{p}<0.05)$. Moreover, the age-related decline in peak oxygen uptake $\left(V^{\prime} \mathrm{O}_{2}\right)$ was lower than previously reported by most of the previous studies and the predicted values for subjects aged $>40$ yrs were systematically higher than estimated by other commonly used equations. Therefore, age-related decline in predicted $V^{\prime} \mathrm{O}_{2}$ from age 20-25 to 65 yrs has been previously estimated to average $20-25 \%$ in sedentary subjects; in contrast, $\mathrm{KOCH}$ et al. [2] reported only a $15 \%$ decrease in males and females. As a consequence, figure 5 from the study by $\mathrm{KoCH}$ et al. [2] shows that the median peak $V^{\prime} \mathrm{O}_{2}$ values predicted by three other equations for subjects aged $\geqslant 65$ yrs were in the lower quartiles or close to the 5 th percentile in males and females, respectively. Collectively, these findings seem to indicate that the reference values of $\mathrm{KocH}$ et al. [2] are of limited value for the evaluation of exercise normalcy in the specific sub-population of sedentary elderly subjects in whom cardiopulmonary diseases are more prevalent [3] and CPET could be clinically more useful.

We have previously reported the findings of a similar, albeit smaller, study in which the subjects were randomly selected from a database of $>8,000$ subjects [4]. Although this study feature increased enormously the complexity of the investigation, it eventually proved essential to obtain truly representative data for clinical interpretation of CPET. For instance, occasional volunteers were submitted to the same evaluation protocol but results were not considered on the final analysis. As expected, they were more active, fitter and leaner than the randomised subjects. In fact, if data from the nonrandomised subjects had been included in the analysis, predicted peak $V^{\prime} \mathrm{O}_{2}$ values would be almost $20 \%$ higher, i.e. values quite similar to those reported by Koch et al. [2]. In our view, this is the main reason that explains why our prediction equations provide the lowest peak $V^{\prime} \mathrm{O}_{2}$ values amongst other sources of reference values, e.g. fig. 5 from $\mathrm{KocH}$ et al. [2]. Moreover, we developed reference values for several effort-independent, submaximal relationships obtained in the incremental phase of exercise [5]. Considering that these variables are less influenced by maximal aerobic capacity, $\mathrm{KoCH}$ et al. [2] might have excellent material in their hands to further contribute to the field.

In conclusion, it is our opinion that the "ideal" set of reference values for clinical interpretation of CPET is still to be generated. Although such investigation would certainly share 
many of the characteristics of the study by $\mathrm{KocH}$ et al. [2], the issue of subject randomisation will be critical to improve our confidence on the limits of normality for key CPET variables.

\section{J.A. Neder}

Respiratory Division, Dept of Medicine, Paulista School of Medicine, Federal University of São Paulo, São Paulo, Brazil.

Correspondence: Federal University of São Paulo, Pulmonary Function and Clinical Exercise Unit, R. Prof Francisco de Castro 54, São Paulo, 04050-032, Brazil. E-mail: albneder@ pneumo.epm.br

Statement of Interest: None declared.

\section{REFERENCES}

1 ERS Task Force, Palange P, Ward SA, et al. Recommendations on the use of exercise testing in clinical practice. Eur Respir J 2007; 29: 185 209.

2 Koch B, Schäper C, Ittermann $\mathrm{T}$, et al. Reference values for cardiopulmonary exercise testing in healthy volunteers: the SHIP study. Eur Respir J 2009; 33: 389-397.

3 Stewart KJ. Physical activity and aging. Ann N Y Acad Sci 2005; 1055 193-206.

4 Neder JA, Nery LE, Castelo A, et al. Prediction of metabolic and cardiopulmonary responses to maximum cycle ergometry: a randomised study. Eur Respir J 1999; 14: 1304-1313.

5 Neder JA, Nery LE, Peres C, Whipp BJ. Reference values for dynamic responses to incremental cycle ergometry in males and females aged 20 to 80. Am I Respir Crit Care Med 2001; 164: 1481-1486

DOI: $10.1183 / 09031936.00030809$

\section{From the authors:}

Based on results of their important studies and assumptions concerning the Study of Health in Pomerania (SHIP) database, J.A. Neder questions the relevance of our report on reference values for cardiopulmonary exercise testing (CPET) [1]. The establishment of close-to-reality reference values for the clinical interpretation of CPET is indeed an important issue since a consensus has not yet been reached on the definition of normalcy. Therefore, we consider our study to be an additional contribution to present an "ideal" set of normative values for CPET. In this context, the major strength of the current study first lies in the use of data from a large population-based sample of adults. Secondly, the consideration of echocardiographical and lung functional data besides comprehensive information on past and current medical history, as well as the performance of all kinds of clinical examination methods contributes exceedingly to the establishment of a disease-free reference sample.

J.A. Neder mainly criticises the issue of voluntary participation and the aspect of too little consideration of physical activity in the current study sample on CPET. At this point, we would like to put emphasis on the fact that the SHIP study sample itself, including the participants in CPET, was randomly selected from the general population via registration offices [2]. Within a democratically ruled country, eventual participa- tion in the study is dependent on voluntary participation. Therefore, one can argue that every epidemiological survey, to some extent, is biased, as stated in the published article; a selection bias towards younger and healthier individuals was evident. However, by means of adjusting for age and applying stringent exclusion criteria towards healthy participants, this should only marginally affect the normative limits for CPET.

J.A. Neder impeaches the applicability of the present reference values in the specific sub-population of sedentary elderly subjects since the described predicted values for peak oxygen uptake $\left(V^{\prime} \mathrm{O}_{2}\right)$ were systematically higher than those previously described. Besides a selection bias towards younger and slimmer volunteers our data may be biased by analysing CPET results of physically more active participants aged $\geqslant 50$ yrs $\left(<2 \mathrm{~h} \cdot\right.$ week $^{-1}$ versus $\geqslant 2 \mathrm{~h} \cdot$ week $\left.^{-1} ; \mathrm{p}<0.01\right)$. Within the group of participants in CPET $(n=534$ versus $n=1,174)$ no significant difference in the levels of physical activity was found $(p=0.241)$. So far, we agree with J.A. Neder. However, in our view the effect of excluding participants with coexisting and as yet unknown diseases has been shown to have an even more important impact in this subpopulation. Due to results derived within the examination process, $74 \%$ of the subjects aged $>50$ yrs had to be excluded. This clearly shows the importance of a wide spectrum of examination methods beside patients self report to detect and consequently exclude coexisting pathologies. NEDER et al. [3] tried hard to establish a disease free study sample, but alike comparable studies to some extent all cardiorespiratory disorders might not have been detected in advance. Furthermore, the majority of studies concerning reference values might be criticised for not being population based and, thus, of limited comparability to our study design. Besides less accurately assessed exclusion criteria, another major shortcoming of other previous studies seems to be the inclusion of individuals who smoke even though an impact of cigarette smoking on exercise capacity assessed by peak $V^{\prime} \mathrm{O}_{2}$ and $V^{\prime} \mathrm{O}_{2}$ at anaerobic threshold has been shown $[4,5]$.

One can easily argue that every existing study on reference values for CPET shows limitations. Nevertheless, every piece of work on this issue seems to contribute to close-to-reality normative values. It is incontrovertible that the present findings are the first considering such an amount of different medical examination methods for the establishment of a healthy study sample across a wide age range. However, everybody working on reference values for CPET should be encouraged to do so, since, and at this point we completely agree with J.A. Neder, the "ideal" set of reference values for CPET might still to be generated.

\section{B. Koch* , C. Schäper*, H. Völzke", R. Ewert* and S. Gläser*} *Dept of Internal Medicine B-Cardiology, Intensive Care, Pulmonary Disease and Infectious Diseases, and "Institute for Community Medicine SHIP / Clinical Epidemiological Research, University Greifswald, Greifswald, Germany.

Correspondence: B. Koch, Medical faculty of the Ernst-Moritz Ardnt University, Dept of Internal Medicine B-Cardiology, Intensive Care, Pulmonary Medicine and Infectious Disease, 